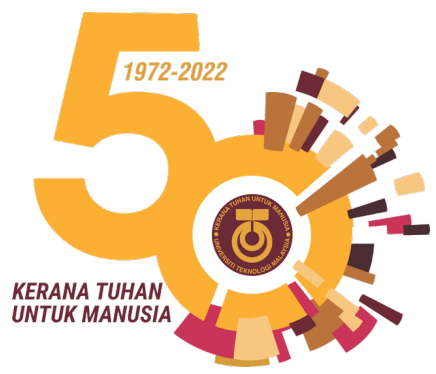

\title{
Phosphorescent Vapochromic Responses of Copper(I) Complex Bearing Pyrazole Ligands for Detection of Alcohol Derivatives
}

\author{
Nur Fatiha Ghazallia,*, Nurul Husna Sabran ${ }^{\mathrm{b}}$, Juan Matmin ${ }^{\mathrm{b}}$, Mohamad \\ Azani Jalanic, Hendrik O. Lintang ${ }^{\mathrm{d}}$
}

a School of Dental Sciences, Health Campus, Universiti Sains Malaysia, Kubang Kerian, 16150 Kota Bharu, Kelantan, Malaysia; ' ${ }^{b}$ Department of Chemistry, Faculty of Science, Universiti Teknologi Malaysia, 81310 Johor Bahru, Johor, Malaysia; c Kolej GENIUS Insan, Universiti Sains Islam Malaysia, Kompleks PERMATA Insan, Bandar Baru Nilai, 71800 Nilai, Negeri Sembilan, Malaysia; ${ }^{d}$ Centre of Sustainable Nanomaterials, Ibnu Sina Institute for Scientific and Industrial Research, Universiti Teknologi Malaysia, 81310 UTM Johor Bahru, Johor, Malaysia

Abstract The methodical study of trinuclear copper(I) metal complexes phosphorescent vapochromic chemosensor via metal-metal interactions for sensing various volatile organic compounds has piqued the interest of many researchers. Herein, we highlighted the performance of chemosensors trinuclear copper $(\mathrm{I})$ pyrazolate complexes $\left(2 \mathrm{Pz}_{1}-2 \mathrm{Pz}_{5}\right)$ with different molecular design short alkyl side chains from the respective pyrazole ligands. The synthesized complexes had demonstrated a high phosphorescent sensing capacity of various alcohol derivatives. Due to weak metal-metal interactions, the complexes give emission bands centered around 553-644 nm at an excitation of $280 \mathrm{~nm}$. We found that the only $2 \mathrm{Pz}_{3}$ chemosensors showed quenching phenomena with a significant decrease in its emission intensity of $100 \%$ for exposure in 5 minutes with irreversible performance. Interestingly, we also found that the shifting of the emission center due to the disruption of metal-metal interaction performed by chemosensor $2 \mathrm{Pz}_{5}$ resulting in the best detection performance of methanol and ethanol $(\Delta \lambda=60 \mathrm{~nm})$ and propanol $(\Delta \lambda=22 \mathrm{~nm})$ showing autonomous recovery within 15 minutes. Based on the findings, the specific balance, such as rigidity and amphiphilicity in the molecular design of chemosensors, is important for the detection of vapors via supramolecular interactions.

Keywords: phosphorescent, pyrazole ligands, metal-metal Interactions, vapochromic chemosensor.

*For correspondence: fatiha85@usm.my

Received: 13 Dec 2021 Accepted: 23 Feb 2022

(C) Copyright Ghazalli et al. This article is distributed under the terms of the Creative Commons Attribution License, which permits unrestricted use and redistribution provided that the original author and source are credited.

\section{Introduction}

Recently, identifying volatile organic compounds (VOCs) has been a significant concern due to the effects of gaseous pollutants emitted maliciously or unintentionally from industrial or combustion engine pollution [1, 2]. Indeed, VOCs and small molecules such as alcohol and benzene derivatives are widely used in chemical, medical, pesticide, cosmetic, paint and other industries. These compounds have a highly toxic or carcinogenic nature that can be easily absorbed into the human skin and respiratory tract, negatively affecting both human health and the natural ecosystem in the short or long term [2, 3]. Currently, many types of research have been reported in developing the combination of two or three nanomaterials or nanocomposites such as carbon nanotubes (CNT), silver $(\mathrm{Ag})$, tin dioxide $\left(\mathrm{SnO}_{2}\right)$, zinc oxide $(\mathrm{ZnO})$, titanium dioxide $\left(\mathrm{TiO}_{2}\right)$, gold nanoparticles, and graphene for the detection of VOCs. Still, most of these novel findings have encountered a few problems that are commonly experienced in using 
other sensing devices, such as low specificity and sensitivity, additional detection modes for signal transduction were not provided and false in sensing of VOCs [4]. Phosphorescent $d^{6}, d^{8}, d^{10}$ metal complexes have been established as vapochromic chemosensors with various advantages from the photophysical characteristics such as emission sensitivity, Stokes shift changes, single-photon stimulation and longer lifetimes [5-7], in the broad $\pi$ (pi) or coordinating donor systems. Therefore, the luminescent transition metal complexes have attracted a great deal of attention for phosphorescence sensing applications due to their attractive photophysical properties and offered some solutions to such problems.

$\mathrm{Li}$ and co-workers have reported the development of phosphorescent chemosensors based on heavy metal complexes [8]. In this case, the transition metal complex as the "signalling unit" transduces the analyte binding event into an optical (luminescent) signal where else the "receptor unit" binding to the analyte of interest and then attached to the metal complex through either a $\sigma$-linker or a $\pi$-linker. As the both types of linkers actually can be used for the design of "switch-on" or "switch-off" luminescent chemosensors based on phosphorescence enhancement or quenching, respectively [9, 10]. The resulting metal complexes have revealed color changes from vapor-triggered luminescence owing to metal-solvent, metal-metal, $\pi-\pi$, and hydrogen bonding and host-guest interactions [11]. In this case, supramolecular phosphorescent metal complexes with their self-assembling properties have been extensively explored as chemosensors due to the possibility of changes in tunability and rigidity $[12,13]$. For example, Nagel and co-workers in 1988 [14] synthesized palladium (Pd) and platinum (Pt) doublecomplex or mixed salt for the detection of vapors. This type of complex was fabricated into fibre optics for the detection of VOCs by Lancaster 1995 [15]. In 1998, Maan and co-workers successfully synthesized Pt-Pt double-complex salt for vapochromic sensors of organic vapors with color, absorption and emission changes [16]. In Group 11, gold complexes or bimetallic gold-silver complexes with various types of ligands have been also reported as chemosensors. Although copper complexes can be synthesized using less expensive precursors and showed a strong luminescent intensity and longer lifetime, they have received less attention as chemosensors so far [17]. Therefore, it would be interesting to develop new phosphorescent chemosensors using copper complexes with high sensing capability for detection of VOCs such alcohol derivatives.

Earlier, this work was reported that phosphorescent trinuclear copper(I) pyrazolate complexes from 3,5dimethyl and 4-(3,5-dimethoxybenzyl)-3,5-dimethyl pyrazole ligands were successfully synthesized and then used for chemosensors of ethanol only [18]. Continuously, the study was carried out by comparing with another types of pyrazole ligands such as non-side chain, 3,5-dimethyl, 3,5-bis(trifluoromethyl) and 3,5-diphenyl pyrazole ligands bearing to trinuclear copper(I) metal complexes for sensing ethanol. Indeed, only the resulting trinuclear copper(I) 4-(3,5-dimethoxybenzyl)-3,5-dimethyl pyrazolate complex showed a positive response to ethanol by shifting the emission band from 604 to $554 \mathrm{~nm}$ where the original intensity can be recovered without external stimuli at room temperature [19]. By considering the molecular design of the phosphorescent trinuclear copper(I) pyrazolate complexes bearing various side chains with different metal-metal distance as a sensing site in an essential [20], it is interesting challenge to focused on the sensing capability of the chemosensors to detect methanol to hexanol rather than only ethanol, in the alcohol family.It is expected that upon exposure to alcohol derivatives, the chemosensors will show the importance of molecular structures in supramolecular self-assembly of single-crystal phosphorescent complexes with different rigidity, electronegativity and metal-metal distance for their sensing capabilities.

\section{Experimental}

\section{Synthesis of Trinuclear Copper(I) Pyrazolate Complexes $\left(2 \mathrm{Pz}_{1}-2 \mathrm{Pz}_{5}\right)$

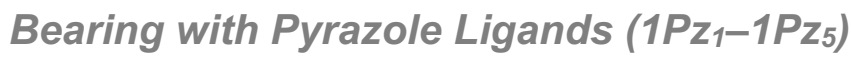

Trinuclear copper(I) pyrazolate complexes $2 \mathrm{Pz}_{1}-2 \mathrm{Pz}_{5}$, showed in Figure 1 were prepared following the synthetic procedure [21, 22] by a Schlenk technique using five types of short alkyl pyrazole ligands from

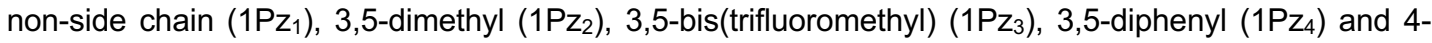




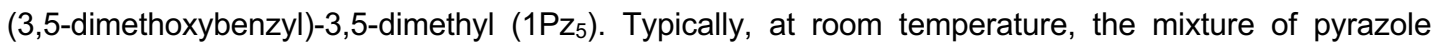
ligand and $\left[\mathrm{Cu}(\mathrm{MeCN})_{4}\right] \mathrm{PF}_{6}$ in tetrahydrofuran $(\mathrm{THF})$ was stirrer for 5 minutes and followed by adding the distilled trimethylamine $\left(\mathrm{Et}_{3} \mathrm{~N}\right)$ under an inert condition. After overnight reaction, THF was removed from the reaction mixture under reduced pressure, and the remaining residues were dried off to isolate the desired complexes. For purification, in-situ recrystallization was carried out by dissolving the desired complexes in DCM $(15 \mathrm{~mL})$ under an inert condition. This solution was added dropwise into dry methanol $(\mathrm{MeOH})$ at room temperature for complexes $2 \mathrm{Pz}_{1}-2 \mathrm{Pz}_{5}$. In this condition, the resulting crystals were filtered by in-situ filtration and followed by washing few time with dry $\mathrm{MeOH}$. The resulting residues were dried off to give solid powder and sticky solid of the $2 \mathrm{Pz}_{1}-2 \mathrm{Pz}_{5}$. The collected complexes were evaporated and then dried under reduce of vacuum pressure to give $2 \mathrm{Pz}_{1}-2 \mathrm{P} \mathrm{z}_{5}$ in $97 \%, 92 \%, 99 \%, 88 \%$ and $85 \%$ yields, respectively.<smiles>[R]c1n[nH]c([R])c1[R]</smiles>

$$
1 \mathrm{Pz}_{1}-1 \mathrm{Pz}_{5}
$$
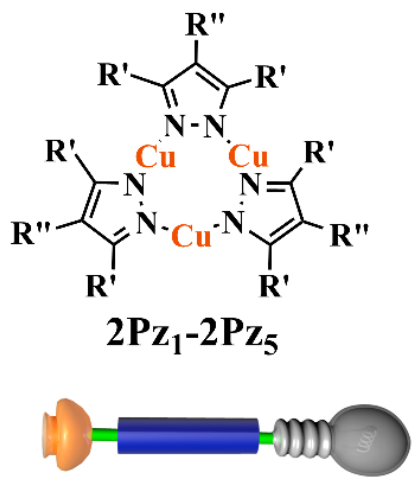

$$
\begin{aligned}
& \mathbf{1 P z}_{\mathbf{1}}: \mathbf{R}^{\prime}=\mathrm{H}, \mathbf{R}^{\prime \prime}=\mathrm{H} \\
& \mathbf{1 P z}_{\mathbf{2}}: \mathbf{R}^{\prime}=\mathrm{CH}_{3}, \mathbf{R}^{\prime \prime}=\mathrm{H} \\
& \mathbf{1 P z}_{\mathbf{3}}: \mathbf{R}^{\prime}=\mathrm{CF}_{3}, \mathbf{R}^{\prime \prime}=\mathrm{H} \\
& \mathbf{1 P z}_{\mathbf{4}}: \mathbf{R}^{\prime}=\mathrm{C}_{6} \mathrm{H}_{5}, \mathbf{R}^{\prime \prime}=\mathrm{H} \\
& \mathbf{1 P z}_{\mathbf{5}}: \mathbf{R}^{\prime}=\mathrm{CH}_{3}, \mathbf{R}^{\prime \prime}=\left(\mathrm{OCH}_{3}\right)_{2} \mathrm{Bn}
\end{aligned}
$$

$\mathbf{2} \mathbf{P} \mathbf{z}_{1}: \mathbf{R}^{\prime}=\mathrm{H}, \mathbf{R}^{\prime \prime}=\mathrm{H}$

$2 \mathbf{P z}_{2}: \mathbf{R}^{\prime}=\mathrm{CH}_{3}, \mathbf{R}^{\prime \prime}=\mathrm{H}$

$\mathbf{2} \mathbf{P z}_{3}: \mathbf{R}^{\prime}=\mathrm{CF}_{3}, \mathbf{R}^{\prime \prime}=\mathrm{H}$

$\mathbf{2} \mathbf{P} \mathbf{z}_{4}: \mathbf{R}^{\prime}=\mathrm{C}_{6} \mathrm{H}_{5}, \mathbf{R}^{\prime \prime}=\mathrm{H}$

2Pz: $: \mathbf{R}^{\prime}=\mathrm{CH}_{3}, \mathbf{R}^{\prime \prime}=\left(\mathrm{OCH}_{3}\right)_{2} \mathrm{Bn}$

Figure 1. Synthetic route of copper(I) complexes $\left(2 \mathrm{Pz}_{1}-2 \mathrm{P} \mathrm{z}_{5}\right)$ from pyrazole ligands $\left(1 \mathrm{Pz}_{1}-1 \mathrm{Pz_{5 }}\right)$.

\section{Evaluation of Sensing Performance}

Chemosensors of $2 \mathrm{Pz}_{1}-2 \mathrm{Pz}_{5}$ in $22 \mathrm{mg}[7,18,19]$ were used to evaluate sensing performance by directly being exposed to $200 \mu \mathrm{L}$ of alcohol vapors (methanol to hexanol) from 0 to 5 minutes. The study was carried out by arranging a cell holder for a spectrofluorophotometer containing the chemosensors into the sealed beaker for exposure in 5 minutes. After completion of the exposure time, the sensing performance was directly evaluated using a spectrofluorophotometer and all photographs of the samples were captured using digital camera according to the experimental conditions.

\section{Results and discussion}

\section{Structures Elucidation of Trinuclear Copper(I) Pyrazolate

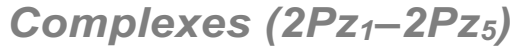

Fourier-transform infrared (FT-IR) and mass spectroscopy measurements were performed in order to observe the characteristic vibration bands of functional groups and molecular weight for the ligands $1 \mathrm{Pz}_{1}-1 \mathrm{Pz}_{5}$ and desired complexes $2 \mathrm{Pz}_{1}-2 \mathrm{Pz}_{5}$. The $\mathrm{FT}-\mathrm{IR}$ spectra of pyrazole ligands and their complexes with characteristic of vibration bands at wavenumber of $3500-500 \mathrm{~cm}^{-1}$ were shown in Figure 2. Based on the spectra obtained, the wavenumber in the range from $3400-3250 \mathrm{~cm}^{-1}$ was assigned to $\mathrm{N}-\mathrm{H}$ (1) stretching from $1^{\circ}$ or $2^{\circ}$ amine group which can be seen in all ligands spectra. These were supported with the strong peaks appeared at 1650-1550 $\mathrm{cm}^{-1}$, representing vibration bands of the $\mathrm{N}-\mathrm{H}$ bending (3). Although the vibration band for $\mathrm{C}-\mathrm{H}$ stretching showed overlap with the $\mathrm{N}-\mathrm{H}$ stretching vibration for the ligands in the range of $3300-3100 \mathrm{~cm}^{-1}, \mathrm{C}-\mathrm{C}(2)$ stretching (in ring) at range 1585-1600 $\mathrm{cm}^{-1}$ were assigned. The complexes $\mathrm{N}-\mathrm{H}$ stretching vibration bands were clearly disappeared in Figure 
2(b), which give $\mathrm{C}-\mathrm{H}$ (1) stretching peak. In this case, the wavenumber at $3000 \mathrm{~cm}^{-1}$ represented the C$\mathrm{H}$ or $=\mathrm{C}-\mathrm{H}-$ stretching from aromatic rings or alkenes group of the complexes. For example, complex $2 \mathrm{Pz}_{1}$ showed the $\mathrm{C}-\mathrm{H}$ stretching vibration band from the non-side chains of the ligand was observed in the spectrum at $3125 \mathrm{~cm}^{-1}$ while others represented the $\mathrm{C}-$ from the methyl group at position of 3-, 5- of the ligands. Based on the mass spectra, the monoisotopic patterns for complexes $2 \mathrm{Pz}_{1}$ and $2 \mathrm{Pz}_{2}$ with the molecular formula of $\mathrm{C}_{9} \mathrm{H}_{9} \mathrm{Cu}_{3} \mathrm{~N}_{6}$ and $\mathrm{C}_{15} \mathrm{H}_{21} \mathrm{Cu}_{3} \mathrm{~N}_{6}$ showed intense peaks at $391.8793 \mathrm{Da}\left(2 \mathrm{Pz} \mathrm{z}_{1}\right)$ and 475.9119 Da $\left(2 \mathrm{Pz}_{2}\right)$ for observed molecular weight of $[\mathrm{M}+\mathrm{H}]^{+}$. For $2 \mathrm{Pz}_{3}$ and $2 \mathrm{Pz}_{4}$ with molecular formula of $\mathrm{C}_{15} \mathrm{H}_{3} \mathrm{Cu}_{3} \mathrm{~F}_{18} \mathrm{~N}_{6}$ and $\mathrm{C}_{45} \mathrm{H}_{33} \mathrm{Cu}_{3} \mathrm{~N}_{6}$, the peaks of molecular weight were observed at 822.3446 Da $(2 \mathrm{Pz})$ and $871.5956 \mathrm{Da}\left(2 \mathrm{Pz}_{4}\right)$ for $[\mathrm{M}+\mathrm{Na}]^{+}$. The monoisotopic patterns for both complexes displayed almost similar to the prediction ones. Moreover, the observed molecular weight for $2 \mathrm{P}_{5}$ was obtained at 927.6032 Da, which was similar to the isotopic pattern with the calculated molecular formula of $\mathrm{C}_{42} \mathrm{H}_{51} \mathrm{Cu}_{3} \mathrm{~N}_{6} \mathrm{O}_{6}$. Therefore, we have successfully synthesized complexes $2 \mathrm{Pz}_{1}-2 \mathrm{Pz}_{5}$ in high yields in the range of 83 to $99 \%$.

(a)

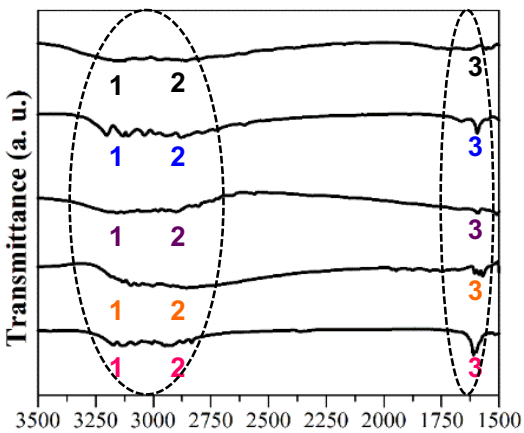

Wavenumber $\left(\mathrm{cm}^{-1}\right)$

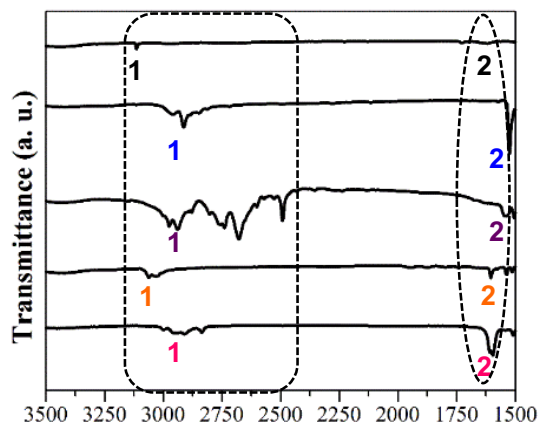

Wavenumber $\left(\mathrm{cm}^{-1}\right)$

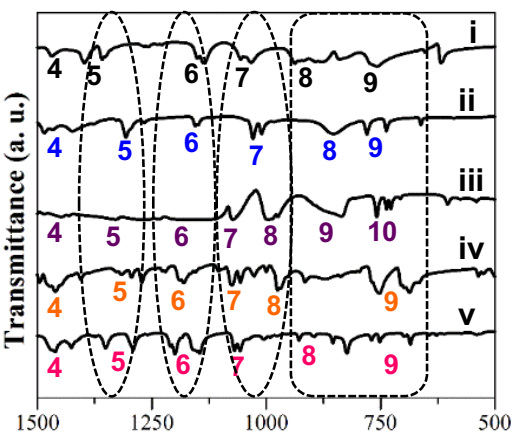

Wavenumber $\left(\mathrm{cm}^{-1}\right)$

(b)

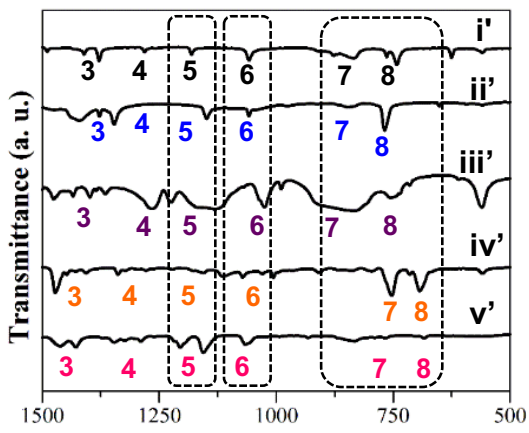

Wavenumber $\left(\mathrm{cm}^{-1}\right)$

Figure 2. FT-IR spectra with the range of $3500-500 \mathrm{~cm}^{-1}$ for pyrazole ligands $(\mathrm{a}, \mathrm{i}) 1 \mathrm{Pz_{1 }},(\mathrm{a}, \mathrm{ii}) 1 \mathrm{Pz_{2 }},(\mathrm{a}$, iii) $1 \mathrm{Pz}_{3}$, (a, iv) $1 \mathrm{Pz}_{4}$ and $(\mathrm{a}, \mathrm{v}) 1 \mathrm{P} \mathrm{z}_{5}$; and trinuclear copper(I) complexes (b,i') $2 \mathrm{Pz}_{1},(\mathrm{~b}, \mathrm{ii}) 2 \mathrm{P} \mathrm{z}_{2},(\mathrm{~b}$, iii') $2 \mathrm{Pz}_{3},(\mathrm{~b}, \mathrm{iv}) 2 \mathrm{Pz_{4 }}$ and $\left(\mathrm{b}, \mathrm{v}^{\prime}\right) 2 \mathrm{P} \mathrm{z}_{5}$.

\section{Optical Characterizations of Chemosensors $2 \mathrm{Pz}_{1}-2 \mathrm{Pz}_{5}$}

Emissions of light have two categories such as fluorescence and phosphorescence. By using the absorption peaks values of pyrazolate complexes, the emission and excitation characterizations were carried out using fluorescence spectrophotometer to find the center of emission band centred of $2 \mathrm{Pz}_{1}-$ $2 \mathrm{Pz}_{5}$, respectively. Based on Figure 3 , the luminescent profiles of $2 \mathrm{Pz} 1-2 \mathrm{Pz} 5$ were observed with emission band centred at ranges from 553 to $639 \mathrm{~nm}$ with wavelength excitation at 275 to $322 \mathrm{~nm}$, summarized in Table 1. The Stokes shift $(\Delta \lambda>200 \mathrm{~nm})$ for each complex showed high values, indicating that all complexes have phosphorescence properties. All complexes $2 \mathrm{Pz}_{1}-2 \mathrm{Pz}_{5}$ showed lifetime ( $\mathrm{T}$ ) in microsecond $(\mu \mathrm{s})$ in the range of 7 to $8 \mu \mathrm{s}$ with $\mathrm{X} 2$ (Chi2) values less than 1 for the best fitting. According to the lifetime characterizations, these results strongly suggested that $2 \mathrm{Pz}_{1}-2 \mathrm{P} \mathrm{z}_{5}$ have phosphorescence properties for metal complexes involving metallophilic interactions. 
(a)

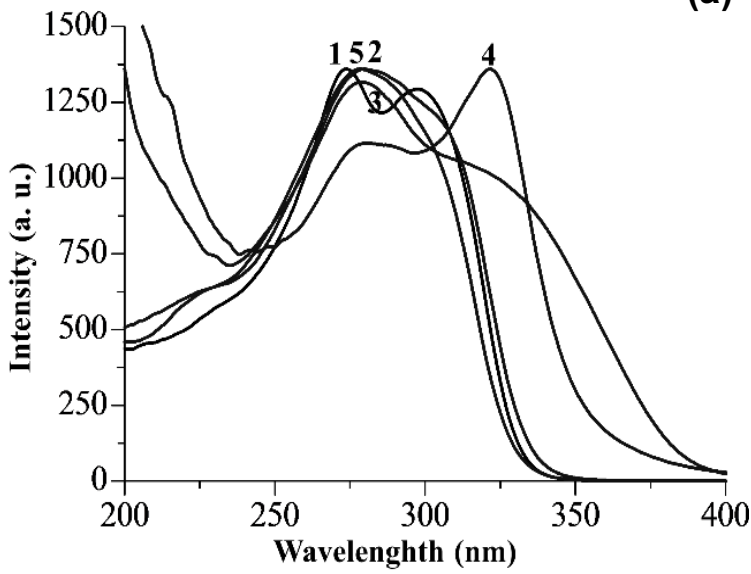

(b)

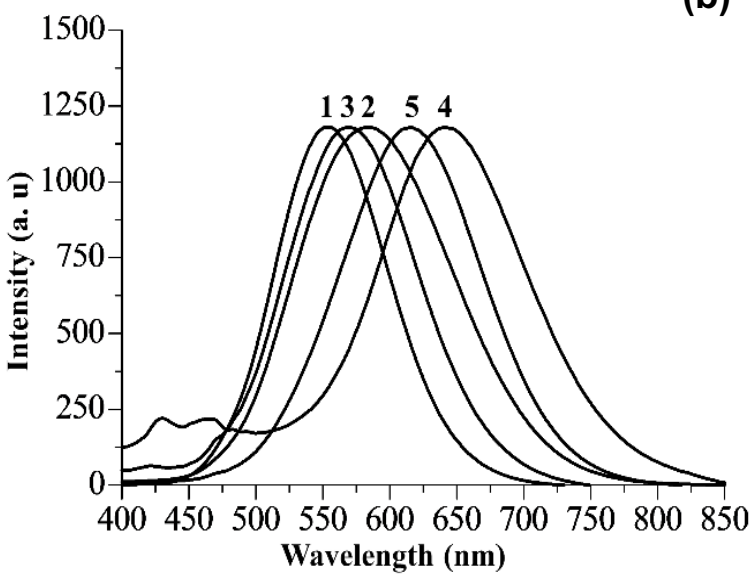

Figure 3. Normalized (a) excitation and (b) emission spectra of $2 \mathrm{Pz}_{1}-1,2 \mathrm{Pz}_{2}-2,2 \mathrm{Pz}_{3}-3,2 \mathrm{Pz}_{4^{-}}-4$ and $2 \mathrm{Pz}_{5^{-}}$ 5.

Table 1. Luminescent excitation, emisson, Stokes Shift and lifetime of $2 \mathrm{Pz}_{1}-2 \mathrm{Pz}_{5}$

\begin{tabular}{ccccc}
\hline Complexes & Excitation $(\mathrm{nm})$ & Emission $(\mathrm{nm})$ & Stokes Shift $(\Delta \Lambda \mathrm{nm})$ & $\begin{array}{l}\text { Luminescent } \\
\text { Lifetime }(\mu \mathrm{s})\end{array}$ \\
\hline $2 \mathrm{Pz}_{1}$ & 274 & 553 & 279 & $7.437 \pm 0.7$ \\
$2 \mathrm{Pz} z_{2}$ & 280 & 584 & 304 & $7.594 \pm 1.5$ \\
$2 \mathrm{Pz} z_{3}$ & 280 & 570 & 290 & $7.370 \pm 0.4$ \\
$2 \mathrm{Pz}_{4}$ & 322 & 644 & 322 & $8.685 \pm 0.3$ \\
$2 \mathrm{Pz}_{5}$ & 278 & 616 & 338 & $8.162 \pm 1.8$ \\
\hline
\end{tabular}
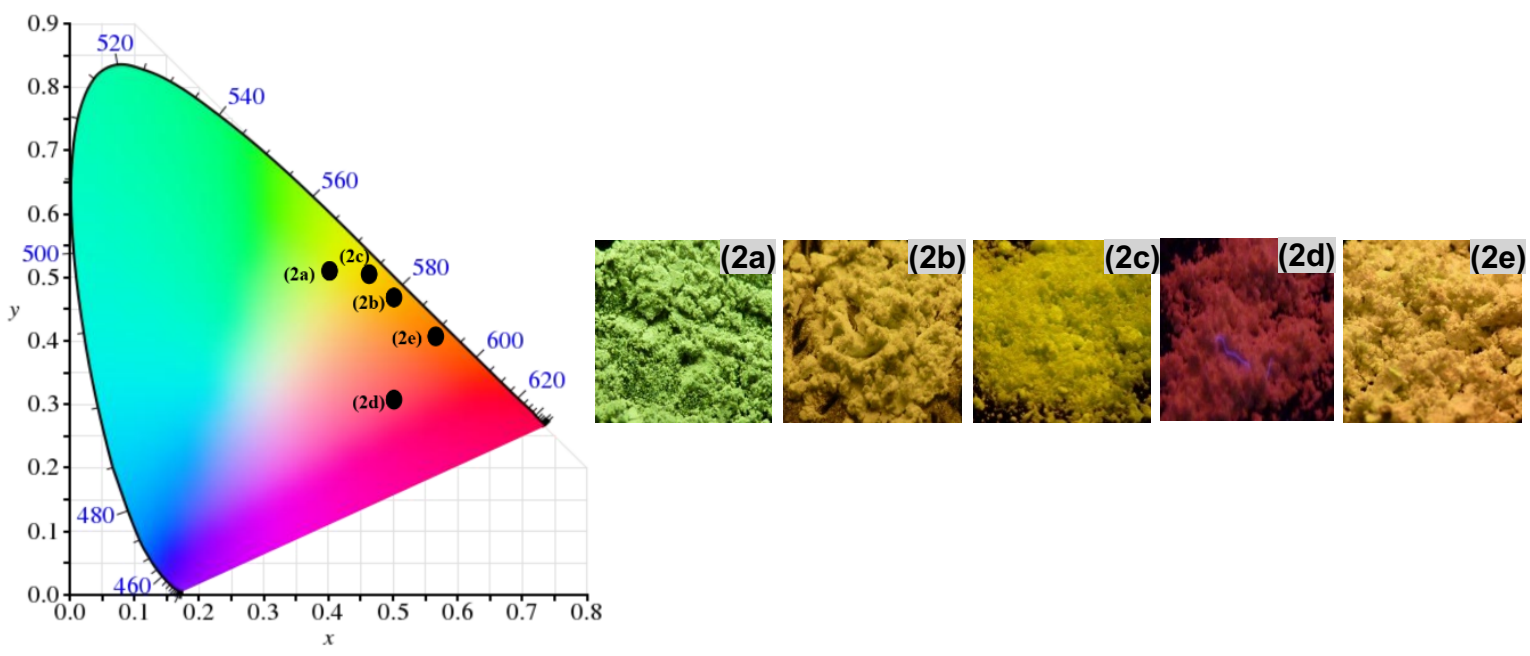

Figure 4. Chromaticity diagram and photo image captured of complexes (2a) $2 \mathrm{Pz}_{1},(2 \mathrm{~b}) 2 \mathrm{P} \mathrm{z}_{2},(2 \mathrm{c}) 2 \mathrm{P} \mathrm{z}_{3},(2 \mathrm{~d}) 2 \mathrm{P} \mathrm{z}_{4}$ and $(2 \mathrm{e}) 2 \mathrm{P}_{5}$ 
To further observation, the CIE color chromaticity with definition as Commission Internationale de l'Eclairage in 1931 was also carried out for $2 \mathrm{Pz}_{1}-2 \mathrm{Pz}_{5}$ complexes. The measurement using spectrophotometer was used to measure the amount of radiation versus wavelength. According to the chart showed in Figure 4, the $x$ and $y$ values were plotted on the chromaticity diagram coordinates indicated the points of saturation colors of compounds, shown in Figure 4(2a-2e). The $x$ and y were calculated according to $X, Y$ and $Z$ tristimulus values observed from the instruments chracterizations. The $X$ represents the red response, $Y$ green response and luminosity, and $Z$ represents the blue response. Basically, the $\mathrm{x}$ and $\mathrm{y}$ chromaticity coordinates were only used to describe in the CIE color system [23].

\section{Evaluation of Sensing Performance by Chemosensors $2 \mathrm{Pz}_{1}-2 \mathrm{Pz}_{5}$ for Detection of Alcohol Derivatives}

Based on the previous works for detecting ethanol vapors, a systematic study has been carried out using derivatives of alcohols such as methanol, propanol, butanol, pentanol, and hexanol. In this case, the comparison of sensing capabilities was discussed in details of chemosensors $2 \mathrm{Pz}_{1}-2 \mathrm{Pz}_{5}$ for detection of methanol to hexanol from 1 to 5 minutes. In Table 2, the best performance of sensing capability was found in two phenomena; $2 \mathrm{Pz}_{3}$ with $100 \%$ quenching in its emission intensity (Figure $5(\mathrm{~b})$, green dot) and $2 \mathrm{Pz}_{5}$ with shifting until saturation in $\Delta \Lambda$ of $61 \mathrm{~nm}$ of its emission intensity (Figure $5(\mathrm{~b})$, black square). For the rest of the chemosensors, the best performance was only achieved in $87 \%$ for $2 \mathrm{Pz}_{4}$ (Figure 5 (b), orange dot) and less than $50 \%$ for $2 \mathrm{Pz}_{1}-2 \mathrm{Pz}_{2}$ (Figure $5(\mathrm{~b})$, red and blue dot). It is expected that typical chemosensors of $2 \mathrm{Pz}_{5}$ with different amphiphilicity showed better sensing capability. By increasing the hydrophobicity of the alcohol derivatives from methanol to hexanol, the sensing capabilities were significantly reduced for the best chemosensors $2 \mathrm{Pz}_{3}$ until $19 \%$ and $2 \mathrm{P} \mathrm{z}_{5}$ until $18 \%$. In detail, the sensing capabilities of chemosensor $2 \mathrm{Pz}_{3}$ were decreased from $100 \%$ with methanol and ethanol, to $96 \%$ with propanol, then to $80 \%, 16 \%$ and $19 \%$ for butanol, pentanol and hexanol, respectively (Figure 5 , green dot). Moreover, the sensing capabilities of $2 \mathrm{Pz}_{5}$ were also significantly reduced from $100 \%$ with methanol and ethanol, to $37 \%$ with propanol, then to $28 \%, 23 \%$ and $18 \%$ for butanol, pentanol and hexanol for exposure in 5 minutes, respectively (Figure 5, black square). Although $2 \mathrm{Pz}_{5}$ can provide the best sensing capability for the detection of methanol and ethanol, it clearly showed decreasing in the performance with increasing hydrophobicity of the VOCs. In the previous paragraph with exposure time in 5 minutes, the sensing capabilities of $2 \mathrm{Pz}_{5}$ were significantly reduced from $83 \%$ to $75 \%, 10 \%, 5 \%, 3 \%$ and $3 \%$ even for $1 \mathrm{~min}$, displayed in Table 2 and Figure 5 (a) and (b), black square. This performance suggests that $2 \mathrm{Pz}_{5}$ is not good enough for sensing alcohols derivatives from propanol and above. Hence, these results indicated that chemosensor $2 \mathrm{Pz}_{3}$ was the best chemosensor for detecting methanol, ethanol, and propanol. In contrast, chemosensor $2 \mathrm{P}_{5}$ tremendously showed its best performance while sensing methanol and ethanol with $100 \%$ sensing capabilities. Subsequently, alcohol derivatives with higher polarity will tend to encourage their vapors to interact via intermolecular hydrogen bonding with the $\mathrm{N}$ atom at the pyrazole ring with chemosensors $2 \mathrm{Pz}_{3}$ to give quenching of the emission intensity and with the $\mathrm{O}$ atom of the methoxy at the benzyl ring with chemosensors $2 \mathrm{Pz}_{5}$ to give shifting of the emission intensity.

Furthermore, reusability testing was also demonstrated on both chemosensors as criteria for selecting sensor materials. Considering the reusability test, only chemosensor $2 \mathrm{Pz} 5$ shall be selected as the best chemosensors for detecting methanol and ethanol but irreversibility performance for chemosensor $2 \mathrm{Pz} \mathrm{z}_{3}$. Moreover, chemosensor $2 \mathrm{Pz}_{5}$ gave perfectly and autonomously recovery of its emission intensity in 15 mins to the original emission centre, shown in Figure 6 (a), red dash line (iii). Moreover, the chemosensor $2 \mathrm{Pz}_{5}$ can be reused up to 10 cycles with sensitivity in LOD of $0.3 \mu \mathrm{L}$. This sensing capability suggests that ethanol vapors can be easily diffused to $O$ atom of methoxy end-groups at the benzyl of metal complexes bearing short alkyl side-chains and then it tends to form an intermolecular hydrogen bonding interaction. 
(a) (b

(c)
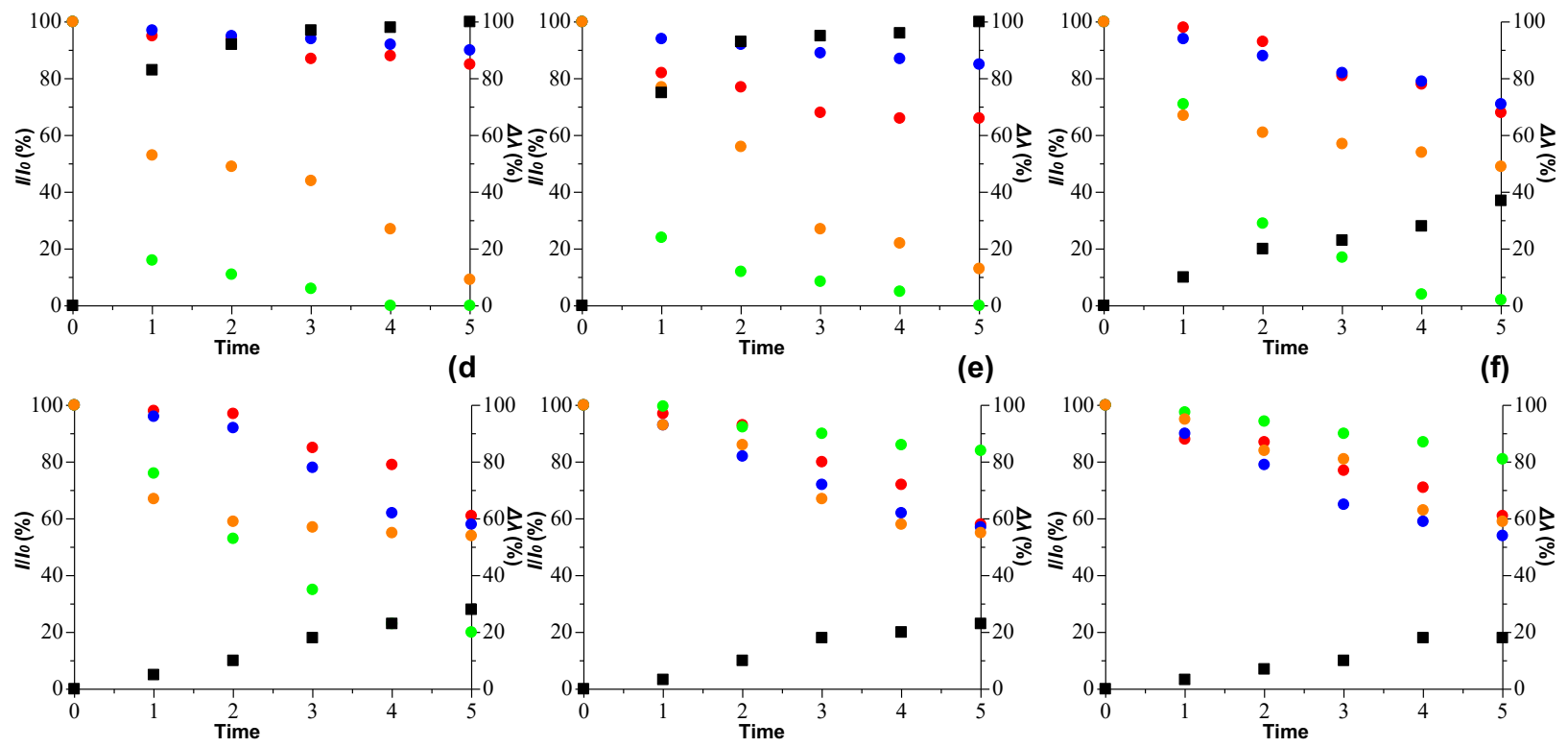

Figure 5. Comparison of sensing capabilities from 0 to 5 mins for detection of (a) methanol, (b) ethanol, (c) propanol, (d) butanol, (e) pentanol and (f) hexanol chemosensors 2Pz1 (red dot), 2Pz2 (blue dot), 2Pz3 (green dot), 2Pz4 (orange dot) and 2Pz5 (black square)

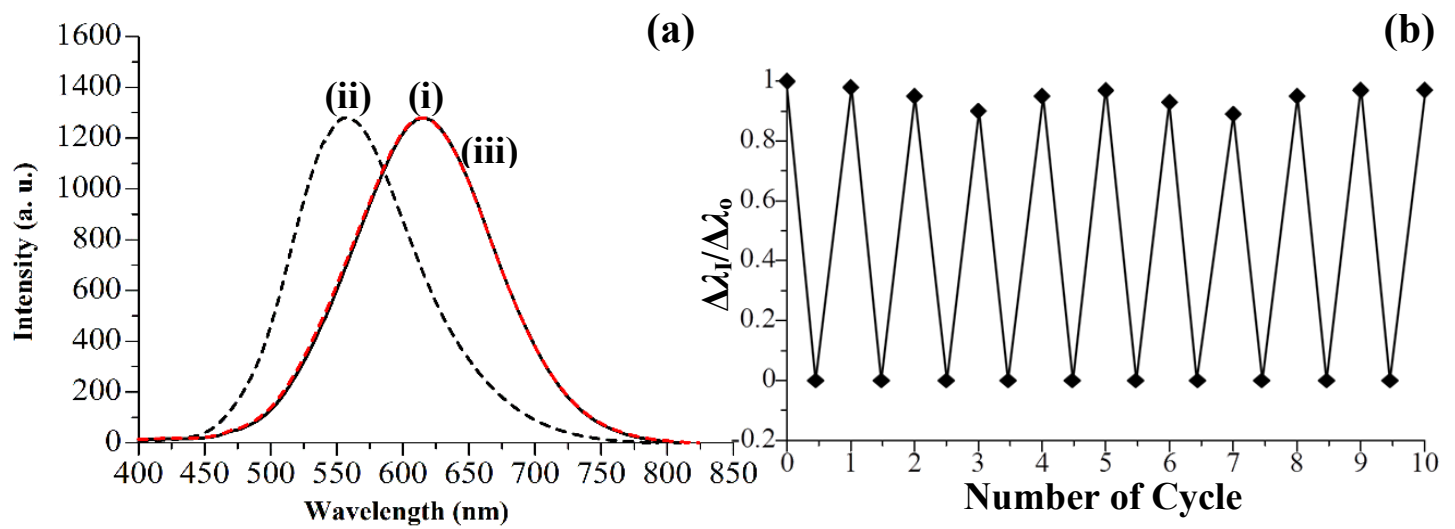

Figure 6. The reversibility and reusability of chemosensor $2 \mathrm{Pz}_{5}$ with (a) emission spectral changes $(\lambda e x t=278 \mathrm{~nm})$ upon exposure to ethanol from 0 (black solid line, i) to 5 mins (black dash line, ii), and the reversible changes (red dash line, iii). 
Table 2. Sensing capability for detection of alcohol derivatives

\begin{tabular}{|c|c|c|c|c|c|c|c|}
\hline \multirow{2}{*}{ Chemosensor } & \multirow{2}{*}{ Emission (nm) } & \multirow{2}{*}{ Vapor $(\mu \mathrm{l})$} & \multicolumn{5}{|c|}{ Sensing Capability (\%) } \\
\hline & & & $1 \mathrm{~min}$ & 2 mins & 3 mins & 4 mins & 5 mins \\
\hline \multirow{6}{*}{$2 \mathrm{P} \mathrm{z}_{1}$} & \multirow{6}{*}{553} & Methanol & 5 & 6 & 13 & 12 & 15 \\
\hline & & Ethanol & 18 & 23 & 32 & 33 & 34 \\
\hline & & Propanol & 2 & 7 & 19 & 22 & 32 \\
\hline & & Butanol & 2 & 3 & 5 & 21 & 39 \\
\hline & & Pentanol & 3 & 7 & 20 & 28 & 42 \\
\hline & & Hexanol & 12 & 13 & 23 & 29 & 39 \\
\hline \multirow{6}{*}{$2 \mathrm{P} \mathrm{z}_{2}$} & \multirow{6}{*}{584} & Methanol & 3 & 5 & 6 & 8 & 10 \\
\hline & & Ethanol & 6 & 7 & 11 & 13 & 15 \\
\hline & & Propanol & 6 & 12 & 18 & 21 & 29 \\
\hline & & Butanol & 4 & 8 & 22 & 38 & 42 \\
\hline & & Pentanol & 7 & 18 & 28 & 38 & 43 \\
\hline & & Hexanol & 10 & 21 & 29 & 41 & 46 \\
\hline \multirow{6}{*}{$2 P z_{3}$} & \multirow{6}{*}{570} & Methanol & 84 & 88 & 96 & 100 & 100 \\
\hline & & Ethanol & 76 & 88 & 91 & 95 & 100 \\
\hline & & Propanol & 29 & 71 & 83 & 90 & 96 \\
\hline & & Butanol & 23 & 47 & 65 & 77 & 80 \\
\hline & & Pentanol & 0 & 7 & 10 & 14 & 16 \\
\hline & & Hexanol & 2 & 6 & 10 & 13 & 19 \\
\hline \multirow{6}{*}{$2 \mathrm{Pz}_{4}$} & \multirow{6}{*}{644} & Methanol & 47 & 51 & 56 & 73 & 91 \\
\hline & & Ethanol & 23 & 44 & 73 & 78 & 87 \\
\hline & & Propanol & 33 & 39 & 43 & 46 & 51 \\
\hline & & Butanol & 33 & 41 & 43 & 45 & 46 \\
\hline & & Pentanol & 7 & 14 & 33 & 42 & 45 \\
\hline & & Hexanol & 5 & 16 & 19 & 37 & 41 \\
\hline \multirow{6}{*}{$2 \mathrm{Pz}_{5}$} & \multirow{6}{*}{616} & Methanol & 83 & 92 & 97 & 98 & 100 \\
\hline & & Ethanol & 75 & 93 & 97 & 98 & 100 \\
\hline & & Propanol & 10 & 20 & 23 & 28 & 37 \\
\hline & & Butanol & 5 & 10 & 18 & 23 & 28 \\
\hline & & Pentanol & 3 & 10 & 18 & 20 & 23 \\
\hline & & Hexanol & 3 & 7 & 10 & 18 & 18 \\
\hline
\end{tabular}

\section{Conclusions}

In conclusion, we have successfully demonstrated series of trinuclear copper(I) pyrazolate complexes with effect of the molecular structures with different alkyl side-chains were evaluated for vapochromic chemosensors of alcohol as well as their derivatives. In the evaluation of sensing capability, response time and reversibility are also important parameters. It clearly showed that the best chemosensors $2 \mathrm{P} \mathrm{z}_{3}$ and $2 \mathrm{Pz}_{5}$ gave "very fast response time" from 1 to 5 mins with different sensing phenomena. Interestingly, chemosensor $2 \mathrm{P}_{5}$ can give $100 \%$ reversibility of its original emission intensity without external stimuli while chemosensor $2 \mathrm{Pz}_{3}$ can only give around $50 \%$ of its original emission intensity Upon exposure to ethanol vapors in 5 mins, chemosensors $2 \mathrm{Pz}_{5}$ showed the best performance with blue-shifting of its emission intensity at 616 to $554 \mathrm{~nm}$, which were in good agreement with the color changes from orange to green. Such performance was achieved by reversibility test with perfect recovery of its original emission intensity at room temperature without external stimuli. The sensing performance indicated chemosensor $2 \mathrm{Pz}_{5}$ with balance in the structural rigidity and amphiphilicity to the sensing site at the particular metal-metal distance for the light emitting capability are the best chemosensor for the detection of methanol and ethanol in alcohol family. For recommendation in future investigations and further 
development, it would be interesting to study the combination of alkyl side-chain that has fluorine molecule with long alkyl chain from hydrophobicity or amphiphilicity types in order to detect different kinds of VOCs. In this case, it would consider to give color changes with competition between shifting to blue range or quenching in intensity with ON/OFF. In addition, systematic research can be carried out to observe the changes in luminescent properties of the chemosensors in-situ by evaluating the changes in lifetime and quantum yield as well as intensity. Moreover, by having chemosensors based on liquid crystal properties which have been reported by Kishimura in 2001, the copper(I) with long alkyl sidechain from different dendritic generation have attracted much intention for this research to study the effect of mobility and orientation of molecules on the sensing capability.

\section{Acknowledgments}

The authors thank Ministry of Higher Education (MOHE), Malaysia for the financial support as well as Centre for Sustainable Nanomaterials, Ibnu Sina Institute for Scientific and Industrial Research (ISI-SIR), Universiti Teknologi Malaysia (UTM), Malaysia for characterization facilities.

\section{References}

[1] H. Jiang, Y. Wang, Q. Ye and G. Zou, "Polydiacetylene-based colorimetric sensor microarray for volatile organic compounds", Sensors and Actuators B, 143(2), 789-794, (2010).

[2] A. D. F. Dunbar, S. Brittle, T. H. Richardson, J. Hutchinson and C. A. Hunter, "Detection of Volatile Organic Compounds Using Porphyrin Derivatives", Journal of Physical Chemistry B, 114 (36), 11697-11702, (2010).

[3] K. Duarte, C. I. L. Justino, A. C. Freitas, A. C. Duarte and T. A. P. Rocha-Santos, "Direct-reading methods for analysis of volatile organic compounds and nanoparticles in workplace air", Trends in Analytical Chemistry, 53, 21-32. (2014).

[4] P. Kumar, A. Deep, K-H. Kim and R. J. C. Brown, "Coordination polymers: Opportunities and challenges for monitoring volatile organic compounds", Progress in Polymer Science, 45, 102-118, (2015).

[5] Q. Zhao, F. Li and C. Huang, "Phosphorescent Chemosensors Based on Heavy-Metal Complexes", Chemical Society Reviews, 39(8), 3007-3030, (2010).

[6] D-L. Ma, V. P-Y. Ma, D. S-H. Chan, K-H. Leung, H-Z. Hea and C-H. Leung, "Recent Advances in Luminescent Heavy Metal Complexes for Sensing”, Coordination Chemistry Reviews, 256(23-24), 3087-3113, (2012).

[7] H. O. Lintang, N. F. Ghazalli and L. Yuliati, "Supramolecular assembly of group 11 phosphorescent metal complexes for chemosensors of alcohol derivatives", IOP Conf. Series: Materials Science and Engineering, 349, 012023 (2018).

[8] Q. Zhao, F. Li, and C. Huang, "Phosphorescent chemosensors based on heavy-metal complexes", Chemical Society Review, 39 (8), 3007-3030, (2010).

[9] D-L. Ma, V. P-Y. Ma, D. S-H. Chan, K-H. Leung, H-Z. He and C-H. Leung, "Recent advances in luminescent heavy metal complexes for sensing", Coordination Chemistry Reviews, 256, 3087-3113, (2012).

[10] X. Zhang, B. Li, Z-H. Chen and Z-N. Chen, "Luminescence vapochromism in solid materials based on metal complexes for detection of volatile organic compounds (VOCs)", Journal of Materials Chemistry, 22 (23), 11427-11441, (2012).

[11] A. Kobayashi and M. Kato, M. "Vapochromic Platinum (II) Complexes: Crystal Engineering toward Intelligent Sensing Devices", European Journal of Inorganic Chemistry, 27, 4469-4483, (2014).

[12] T. W. Bell and N. M. Hext, Supramolecular optical chemosensors for organic analytes, Chemical Society Reviews, 33 (9), 589-598, (2014).

[13] F. Mancin, E. Rampazzo, P. Tecilla and U. Tonellato, "Self-assembled fluorescent chemosensors", Chemistry—A European Journal, 12 (7), 1844-1854, (2006).

[14] C.C. Nagel, Preparation of vapochromic double complex salts, Europ. Patent Appl. EP, 277003, (1998).

[15] G. D. Lancaster, G. A. Moore, M. L. Stone and W. K. Reagen, Volatile organic compound sensing devices, U.S. Patent 5, 445795, (1995).

[16] K. R. Mann, C. A. Daws, C. L. Exstrom, D. E. Janzen and M. Pomije, Vapochromic platinum-complexes and salts, U.S. Patent 5, 766952, (1998).

[17] O.S. Wenger, "Vapochromism in Organometallic and Coordination Complexes: Chemical Sensors for Volatile Organic Compounds", Chemical Reviews,113 (5), 3686-3733, (2013).

[18] N. F. Ghazalli, L. Yuliati, S. Endud, M. Shamsuddin and H. O. Lintang, Vapochromic Copper(I) Pyrazolate Complex Materials for Phosphorescent Chemosensors of Ethanol, Advanced Materials Research, 970, 4447, (2014).

[19] H. O. Lintang, N. F. Ghazalli and L. Yuliati, Supramolecular Phosphorescent Trinuclear Copper(I) Pyrazolate Complexes for Vapochromic Chemosensors of Ethanol, Indonesian Journal of Chemistry, 17, 191-202, 
(2017).

[20] M. A. Omary, M. A. Rawashdeh-Omary, M. W. A Gonser, O. Elbjeirami, T. Grimes and T. R. Cundari, "Metal Effect on the Supramolecular Structure, Photophysics, and Acid-Base Character of Trinuclear Pyrazolate Coinage Metal Complexes", Inorganic Chemistry, 44(23), 8200-8210, (2005).

[21] A. Kishimura, T. Yamashita and T. Aida, T. "Phosphorescent Organogels via "Metallophilic" Interactions for Reversible RGB-Color Switching", Journal of the American Chemical Society, 127 (1), 179-183, (2005).

[22] M. Enomoto, A. Kishimura and T. Aida, "Coordination metallacycles of an achiral dendron self-assemble via metal-metal interaction to form luminescent superhelical fibers", Journal of the American Chemical Society, 123 (23), 5608-5609T, (2001).

[23] A. Kobayashi and M. Kato, "Vapochromic Platinum (II) Complexes: Crystal Engineering toward Intelligent Sensing Devices", European Journal of Inorganic Chemistry, 27, 4469-4483, (2014). 